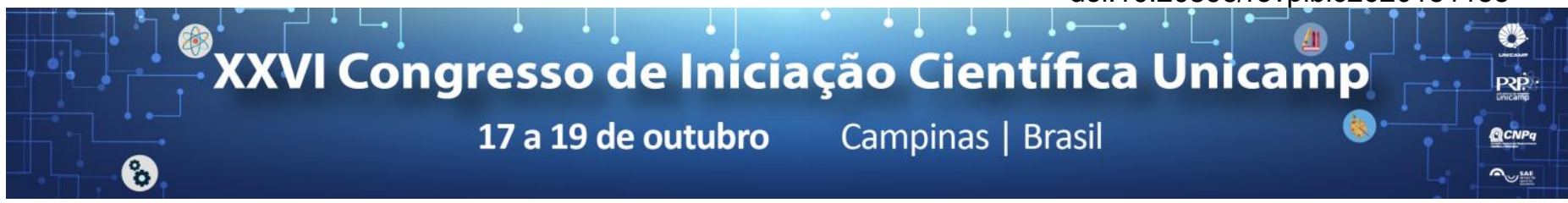

\title{
Avaliação Sensorial de Chocolate ao Leite Adicionado de Mirtilo Liofilizado com Diferentes Tempos de Conchagem
}

\section{Raquel Linhares de Freitas*, Valdecir Luccas, Helena Maria André Bolini.}

\section{Resumo}

O estudo foi realizado com 6 amostras de chocolate ao leite adicionado de mirtilo liofilizado, produzidos com diferentes tempos de conchagem. As amostras foram analisadas sensorialmente por testes afetivos em relação à aparência, aroma, textura, sabor e impressão global, não diferindo significativamente entre elas, exceto o atributo aroma ( $p<0,05)$.

Palavras-chave:

Análise Sensorial, chocolate, mirtilo.

\section{Introdução}

O processo de conchagem é responsável por eliminar sabores e aromas indesejáveis, que são os compostos presentes como sabores ácidos e adstringentes na boca, e por desenvolver aromas agradáveis. Esse processo é realizado através de um processo de agitação, que ocorre em um tanque, com aquecimento e ventilação. Isso permite que os componentes voláteis escapem e o fluido seja modificado. Por esse motivo, chocolates com maior tempo de conchagem, apresentam um gasto energético maior, consequentemente apresentando maior preço e valor agregado ${ }^{1}$.O objetivo do estudo foi avaliar a aceitação de 6 amostras de chocolate ao leite adicionado de mirtilo liofilizado que passaram por 6 diferentes tempos de conchagem e verificar diferença significativa que justifique um tempo maior do processo.

\section{Resultados e Discussão}

Foi desenvolvido 6 formulações de chocolate ao leite adicionado de mirtilo no Instituto de Tecnologia de Alimentos (ITAL). Os tempos de conchagem foram 6, 12, 24, 36, 48 e 72 horas. Foi realizada uma análise de aceitação das amostras com 120 consumidores, utilizando escala não estruturada de $9 \mathrm{~cm}$. Foi aplicado análise estatística ANOVA $(p<0,05)^{2}$. Os resultados estão representados na Tabela 1.

Tabela 1. Médias* de Tukey para aceitação de chocolate ao leite adicionado de mirtilo com diferentes tempos de conchagem.

\begin{tabular}{|c|c|c|c|c|c|}
\hline Amostra & Aparência & Aroma & Textura & Sabor & $\begin{array}{c}\text { Impressão } \\
\text { Global }\end{array}$ \\
\hline $\mathbf{6 h}$ & $7,03 \mathrm{a}$ & $6,14 \mathrm{ab}$ & $6,43 \mathrm{a}$ & $6,97 \mathrm{a}$ & $6,67 \mathrm{a}$ \\
\hline $\mathbf{1 2 h}$ & $7,17 \mathrm{a}$ & $5,90 \mathrm{~b}$ & $6,64 \mathrm{a}$ & $6,76 \mathrm{a}$ & $6,86 \mathrm{a}$ \\
\hline $\mathbf{2 4 h}$ & $7,22 \mathrm{a}$ & $6,72 \mathrm{a}$ & $7,05 \mathrm{a}$ & $6,97 \mathrm{a}$ & $7,27 \mathrm{a}$ \\
\hline $\mathbf{3 6 h}$ & $6,85 \mathrm{a}$ & $5,80 \mathrm{~b}$ & $6,47 \mathrm{a}$ & $6,75 \mathrm{a}$ & $6,66 \mathrm{a}$ \\
\hline $\mathbf{4 8 h}$ & $7,31 \mathrm{a}$ & $6,04 \mathrm{ab}$ & $6,80 \mathrm{a}$ & $6,67 \mathrm{a}$ & $6,85 \mathrm{a}$ \\
\hline $\mathbf{7 2 h}$ & $7,14 \mathrm{a}$ & $6,24 \mathrm{ab}$ & $6,73 \mathrm{a}$ & $6,72 \mathrm{a}$ & $6,88 \mathrm{a}$ \\
\hline
\end{tabular}

* Médias marcadas com letras iguais numa mesma coluna não diferem estatisticamente $(p<0,05)$ pelo teste de médias de Tukey

De acordo com a análise estatística, não houve diferença significativa dos atributos aparência, textura, sabor e impressão global. $\mathrm{O}$ único atributo com diferença significativa foi o aroma e a amostra com maior aceitação foi a de $24 \mathrm{~h}$, que não diferiu das amostras de $6 \mathrm{~h}, 48 \mathrm{e}$ $72 \mathrm{~h}$.

Foi também questionado qual valor máximo que o consumidor pagaria por cada amostra. Como representado na Figura 1, a maioria das pessoas pagariam até $R \$ 9,00$ por $100 \mathrm{~g}$ do produto. Não foi percebido um aumento no limite máximo que o consumidor estaria disposto a pagar conforme aumentou o tempo de conchagem.

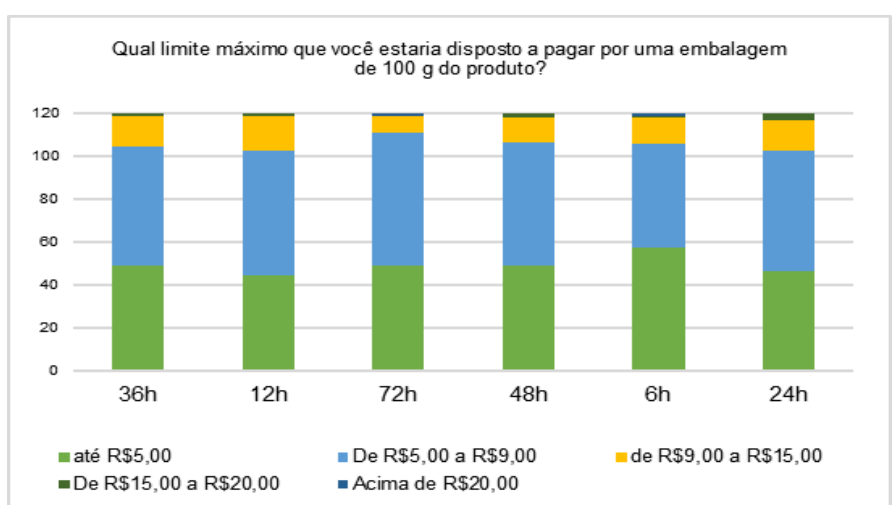

Figura 1. Gráfico do limite máximo que o consumidor pagaria por cada uma das amostras.

Como também observado no mapa de preferência interno, houve uma distribuição homogênea dos consumidores ao redor das amostras, demonstrando que não houve uma amostra com aceitação maior que as outras. Portanto, um maior gasto energético e maior demanda de tempo do processo não foram justificados pelos resultados obtidos.

\section{Conclusões}

Não houve diferença de aceitação entre os diferentes tempos de conchagem para chocolate ao leite adicionado de mirtilo. Também não foi observado um aumento do preço que o consumidor estaria disposto a pagar pelas amostras. Portanto, não há um argumento do ponto de vista sensorial que justifique o emprego do maior tempo de conchagem.

\section{Agradecimentos}

Agradeço a técnica e pós-graduandos do laboratório por todo 0 suporte durante 0 trabalho. Agradeço 0 pesquidador Dr. Valdecir Luccas pela parceria e o CNPQ pelo financiamento deste projeto. Agradeço também minha orientadora Dra Helena Bolini pelo apoio, confiança e amizade durante a pesquisa.

1 BECKETT, S. T. Traditional chocolate making. In: Industrial Chocolate Manufacture and Use. London: Black Academic \& Professional, 2009. p. 1-7.

${ }^{2}$ SCHUTZ, H. G.; CARDELLO, A. V. A labeled affective magnitude (LAM) scale for assessing food liking/disliking. Journal of Sensory Studies, v.16, p. 117-159, 2001. 